Vol. 20(2011): 206-216.

\title{
Improved extraction of prolamins for gluten detection in processed foods
}

\author{
Päivi Kanerva*, Tuula Sontag-Strohm, Outi Brinck and Hannu Salovaara \\ Department of Food and Environmental Sciences, PO Box 66, FI-00014 University of Helsinki, Finland \\ e-mail:paivi.kanerva@helsinki.fi
}

\begin{abstract}
A problem in gluten analysis has been inconsistent extractability of prolamins, particularly from processed foods consisting of unknown portions of prolamins from wheat, barley, and rye. This study aimed at improving the extraction of prolamins for immunological analysis, regardless of the cereal species and the production process. The prolamins were extracted with varying concentrations of ethanol, 1-propanol, and 2-propanol. Sodium dodecyl sulphate-polyacrylamide gel electrophoresis and Western blotting were applied to study the protein composition of the extracts and the antibody recognition of the prolamin subgroups. We characterized the affinities of prolamin-specific antibodies that are used in gluten analysis against the prolamin groups that were soluble in 40\% 1-propanol. The antibody R5 recognized more abundantly the medium-molecular weight groups, including polymeric proteins, and less the high-molecular weight groups than the anti- $\omega$-gliadin antibody. In the present study, the prolamins were most efficiently extracted by $40 \%$ 1-propanol with $1 \%$ dithiothreitol at $50{ }^{\circ} \mathrm{C}$. The prolamins were extracted from processed bread samples with efficiency similar to that from untreated meal samples.
\end{abstract}

Key-words: barley; celiac disease; gluten; prolamin; rye; wheat

\section{Introduction}

Gluten intolerance is one of the most common food intolerances in the Western countries. Currently, its prevalence is about $1 \%$ and has been increasing during recent years (Lohi et al. 2007). People with gluten intolerance must maintain a gluten-free diet, which means excluding wheat, barley, or rye proteincontaining products from the diet. By avoiding these products, gluten-intolerant people are able to keep their intestinal mucosa healthy and live normal healthy lives. However, following a gluten-free diet can be very difficult, since these cereals are widely used. Many products made of gluten-free 
Vol. 20(2011): 206-216.

cereals, such as maize, rice, and oats, may contain proteins from wheat, barley, and rye as contaminants, and therefore result in risk for people with gluten intolerance. The safety of gluten-free products for people with gluten intolerance is controlled by gluten enzyme-linked immunosorbent assays (ELISA) (e.g. Skerritt and Hill 1990, Valdés et al. 2003, Morón et al. 2008). These gluten methods are able to detect very low levels of prolamin proteins, and new limits for acceptable gluten contents in gluten-free products have been set by the European Union (Commission regulation (EC) No 41/2009). Products that can be included in a gluten-free diet are divided into two groups, one of which is gluten-free products and the other products with very low levels of gluten. The gluten-free products may contain a maximum of $20 \mathrm{mg}$ of gluten per $\mathrm{kg}$ of food and the products with very low gluten contents may contain between 20 and $100 \mathrm{mg}$ of gluten per $\mathrm{kg}$ of food.

Gluten in the context of celiac disease refers to proteins that are harmful to people with gluten intolerance. These are the prolamin proteins of wheat, barley, and rye. Prolamin proteins are - by one definition - aqueous-alcohol soluble; however, some of them form alcohol-insoluble structures (Shewry and Halford 2002). Nevertheless, these prolamins become soluble in alcoholic solutions in reduced form. Wheat prolamins are called gliadins and glutenins, barley prolamins hordeins and rye prolamins secalins. The prolamin group consists of monomeric and polymeric proteins. Monomeric prolamins may contain disulfide bonds in their inner structure, whereas polymeric prolamins are joined together by the disulfide bonds, forming large protein complexes (Shewry et al. 1984). The disulfide bonds can be broken by a reducing agent such as dithiothreitol (DTT) or 2-mercaptoethanol. The opening of the disulfide bonds of polymeric prolamins is needed to enhance the solubility of polymeric prolamins in aqueous alcohol solutions. The prolamins of wheat, barley, and rye have different relative contents of monomeric and polymeric prolamins. The ratio between monomeric and polymeric prolamins in wheat is between 1.5 and 3.1 and in barley between 1.4 and 5.0 (Wieser and Koehler 2009). The ratio in rye is between 6.2 and 8.2 (Gellrich et al. 2003).
Two important parameters affect the quantitative analysis of prolamins. The first is the solubility of prolamins in the extraction solution, and the second is the antibody recognition of the prolamin subgroups. In immunological gluten assays, prolamins are commonly extracted with $60 \%(\mathrm{v} / \mathrm{v})$ ethanol with or without reduction of disulfide bonds. However, previous studies indicate that other alcoholic solutions, such as aqueous propanol, extract more prolamins from the samples than aqueous ethanol (Lauriére et al. 1976, Shewry et al. 1980, Shewry et al. 1983). The recommended extraction method with sandwich R5 ELISA analysis for processed food samples is the so-called cocktail extraction. The cocktail extraction solution contains 2-mercaptoethanol as a reducing agent and guanidine hydrochloride as a disaggregating reagent to improve protein solubility. Whether prolamins are extracted in their native or reduced form has considerable impact on the extraction yield and the composition of the extract. Due to the assumption that wheat contains about equal halves of the prolamins that require reduction (glutenins) and those that do not (gliadins), the results are multiplied by two to obtain the total gluten content. Multiplication is necessary only if the prolamins are extracted without reduction; however, it is not correct to multiply the results of the samples that are extracted in the presence of a reducing agent, since the sample already contains the total gluten fraction. The degree of multiplication has also been questioned (Wieser and Koehler 2009). However, there remains the question of whether the antibody can recognize all of the prolamin groups that are extracted.

Processing of food alters the properties and the conformation of proteins. Therefore, it is highly important to determine the solubility of proteins from products that have undergone different processes. The most common process is heating. Heating, e.g. during baking, denatures the proteins and, thus, decreases significantly their solubility in common extraction solutions (Lagrain et al. 2005). Proteins may also be hydrolyzed into smaller peptides during the process (e.g. in fermentation processes and brewing), which usually increases their solubility. Some food products undergo extrusion or enzymatic treatments during processing, both of 
Kanerva, P. et al. Extraction of prolamins

which significantly change the solubility of proteins. The high pressure denatures proteins and decreases their solubility. The decreased solubility of denatured proteins has raised concern and the reduction of the proteins in heat-processed samples is recommended during extraction. The reduction breaks the disulfide bonds and improves the solubility of the proteins. However, the heat- and pressure-induced changes are not the only reason for using reduction during extraction. The polymeric prolamins contain natural disulfide bonds in their structure. To extract the total prolamin fraction of the samples, the reduction should also be used for samples that are not heat-processed.

The aim of this study was to determine the extractability of wheat, barley, and rye prolamins from bread samples that were processed by different techniques including commercial yeast bread process and sourdough processes, and baking without yeast. To our knowledge, the optimization of prolamin extraction has only been shown for meal and baked wheat samples, not for baked rye and barley products. Since gluten analyses are performed in processed samples, we focused on optimization of the extraction of prolamins from the processed bread samples. Furthermore, two prolamin-specific antibodies were compared in this study for their ability to recognize different prolamin groups of wheat, barley, and rye.

\section{Materials and methods}

\section{Meal and bread samples}

The wheat, barley, and rye grains were obtained from Boreal Plant Breeding Ltd, Finland. The wheat samples consisted of the cultivars Aura, Ilves, Kadett, Nisu, Polkka, Runar, Ruso, Satu, Tjalve, and Tähti. The barley samples consisted of the cultivars Annabell, Erkki, Inari, Jyvä, Kunnari, Minttu, Polartop, Rolfi, Saana, and Voitto. Ten rye samples consisted of four cultivars: Akusti, Amilo, Bor9415, and Picasso, which were grown at six different locations in Finland between 2001 and 2006.
Equal amounts of the grains of each cultivar were measured, mixed, and milled with a laboratory pin mill (KT-30, Koneteollisuus Oy, Finland) to make wheat, barley, and rye meals. The barley meal was sieved after milling with a $600-\mu \mathrm{m}$ sieve to remove the larger seed coat parts.

The three bread samples included: 1) a wheat bread that was a yeast-leavened toasting bread (Vaasan Arki Vehnäpaahto, Vaasan Oy, Estonia), 2) a flat barley bread that was homebaked using barley meal (Sunnuntai, Raisio Oyj, Finland), water, and salt (no yeast added), and 3) a rye loaf bread made by a sourdough process (Uotilan Aito Pälkäneen Maalaislimppu, Uotilan Leipomo Oy, Finland).

The details of the samples are listed in Table 1. The moisture and ash contents were determined using the methods of the American Association of Cereal Chemists: AACC 44-15A and AACC 08-02. The protein contents were analyzed wit the Dumas combustion method (Vario MAX CN, Germany) using $\mathrm{N}$ x 5.7 for wheat and $\mathrm{N}$ x 6.25 for barley and rye (AACC method 46-30).

\section{Sample extraction}

The wheat, barley, and rye meals were extracted with ethanol, 1-propanol, or 2-propanol in aqueous alcohol concentrations of $20 \%, 30 \%, 40 \%, 50 \%$, $60 \%$ and $70 \%(\mathrm{v} / \mathrm{v})$. In all, $160 \mathrm{mg}$ of meal were extracted with $1.6 \mathrm{ml}$ of alcohol solution for 20 min at $21{ }^{\circ} \mathrm{C}$ or $50{ }^{\circ} \mathrm{C}$ with continuous shaking at

Table 1. Moisture, ash, and protein contents of the meal and bread samples (dry weight).

\begin{tabular}{llccc}
\hline Sample & & $\begin{array}{c}\text { Moisture } \\
\%\end{array}$ & $\begin{array}{c}\text { Ash } \\
\%\end{array}$ & $\begin{array}{c}\text { Protein } \\
\%\end{array}$ \\
\hline Meal & Wheat & 11.6 & 1.55 & 14.5 \\
& Barley & 11.4 & 2.24 & 13.8 \\
& Rye & 11.3 & 1.57 & 11.9 \\
Bread & Wheat & 29.2 & n.d. & 12.8 \\
& Barley & 41.2 & n.d. & 9.7 \\
& Rye & 42.9 & n.d. & 11.2 \\
\hline
\end{tabular}

n.d. $=$ not determined 
Vol. 20(2011): 206-216.

approximately 330 rounds per min in an incubator (Heidolph Inkubator 1000, Germany). For the reduced samples $1 \%, 2 \%, 4 \%, 6 \%$ and $8 \%(\mathrm{w} / \mathrm{v})$ DTT was added to $50 \% 1$-propanol and the extraction was performed at $50{ }^{\circ} \mathrm{C}$ for $20 \mathrm{~min}$. After extraction, the samples were centrifuged at $15800 \mathrm{~g}$ for $10 \mathrm{~min}$ and the supernatants collected. All of the extractions were performed in triplicate. The protein contents were analyzed with the Dumas combustion method.

A sequential extraction following a modified Osborne fractionation was performed for the sodium dodecyl sulfate - polyacrylamide gel electrophoresis (SDS-PAGE) analysis (Osborne 1907). The meals were first extracted three times with distilled water and then three times with $0.5 \mathrm{M} \mathrm{NaCl}$ at room temperature. Then the precipitates were washed briefly with water before extraction three times with $40 \% 1$-propanol at $50{ }^{\circ} \mathrm{C}$, three times with $40 \%$ 1-propanol and $1 \%$ DTT at $50{ }^{\circ} \mathrm{C}$ and three times with SDS sample buffer (4\% (w/v) SDS, $20 \%$ (v/v) glycerol, $125 \mathrm{mM}$ tris(hydroxymethyl) aminomethane, $1 \%(\mathrm{w} / \mathrm{v})$ DTT, bromophenol blue, $\mathrm{pH} 8.5)$.

The bread samples were extracted with $40 \%$ 1-propanol containing $1 \%$ DTT at $50^{\circ} \mathrm{C}$ and $60^{\circ} \mathrm{C}$ for $30 \mathrm{~min}$ or $60 \mathrm{~min}$. Two sample:solution ratios of 1:40 and 1:10, which are commonly used in the extraction protocols before the immunological gluten analysis, were compared. The efficiency of the extraction was compared with that of the cocktail extraction (R7006, R-Biopharm, Germany) which was recommended for use with the sandwich R5 ELISA. The protein contents were analyzed with the Dumas method, and the method of Lowry et al. (1951) was used to compare the extraction protocol with the cocktail extraction.

\section{SDS-PAGE and Western blotting with $\omega$-gliadin, R5, and polyclonal antigliadin antibodies}

The samples were concentrated by allowing $100 \mu 1$ of the meal sample extracts to evaporate to dryness at room temperature. The dried samples were solubilized in $40 \mu 1$ of SDS sample buffer. The proteins were separated in a NuPage gradient mini $(8 \mathrm{~cm} \times 8$ $\mathrm{cm})(4-12 \%)$ Bis-Tris [Bis(2-hydroxyethyl)iminotris(hydroxymethyl)methane-HCl] gel (NP0322, Invitrogen, USA). A NuPage 2-(N-morpholino) ethanesulfonic acid (MES) - SDS running buffer was used with NuPAGE antioxidant (NP0002 and NP0005, Invitrogen, USA). The run was done at $150 \mathrm{~V}$ and the running time was $70 \mathrm{~min}$. A Novex Sharp Pre-stained Standard was used as a molecular marker (LC5800, Invitrogen, USA).

After electrophoretic separation, the proteins were transferred to polyvinylidene fluoride (PVDF) membranes (162-0177, BioRad Laboratories, USA) in $25 \mathrm{mM}$ tris(hydroxymethyl) aminomethane, $192 \mathrm{mM}$ glycine, and 20\% (v/v) methanol. The transfer was performed at $30 \mathrm{~V}$ in one hour. After blocking with $1 \%(\mathrm{w} / \mathrm{v})$ bovine serum albumin (BSA; A-6793, Sigma-Aldrich Corp., USA), the membrane was incubated in a solution of either a conjugated anti- $\omega$-gliadin antibody (SA GL0301, Diffchamb, France), a conjugated antibody R5 (Ridascreen Gliadin, R7001, R-Biopharm, Germany) or a polyclonal rabbit anti-gliadin antibody (G9144, Sigma-Aldrich Corp., USA). The conjugated anti- $\omega$-gliadin antibody and the conjugated antibody R5 were diluted to $1 / 250$ and $1 / 22$, respectively, with the dilution buffers provided by the assays. Sodium azide and BSA were added to the buffers. After incubation, the membranes were washed and stained with tetramethylbenzidine (W4121, Promega Corp., USA). The third membrane was incubated with the polyclonal anti-gliadin antibody (1/1000 in a buffer of $50 \mathrm{mM}$ Trisma base, $0.9 \% \mathrm{NaCl}, 0.05 \mathrm{ml}$ Tween, $1 \% \mathrm{BSA}, 0.02 \%$ $\mathrm{NaN}_{3}, \mathrm{pH}$ 7.5). After incubation with anti-gliadin antibody, the membrane was further incubated with anti-rabbit immunoglobulin G (Fc) AP conjugate (S3731, Promega Corp., USA) (diluted to 1/7500 with the same buffer) and stained with BioRad AP conjugate $\mathrm{A}$ and $\mathrm{B}$. The polyclonal anti-gliadin antibody was used to compare the results obtained with the $\omega$-gliadin and the R5 antibodies, due to its ability to recognize prolamins on a wider scale. 
Kanerva, P. et al. Extraction of prolamins

\section{Results}

\section{Optimizing the extraction temperature, reducing conditions, and alcohol concen- tration in the meal samples}

The extraction temperature, reducing conditions, and alcohol concentration were optimized in the meal samples. The temperature used during extraction had a significant effect on the extraction yield. Elevation of the extraction temperature from room temperature $\left(21^{\circ} \mathrm{C}\right)$ to $50^{\circ} \mathrm{C}$ increased the protein yields by $20-30 \%$. Heating especially increased the extractability of high-molecular weight (HMW) and polymeric proteins of the cereals. Since heating to 50 ${ }^{\circ} \mathrm{C}$ significantly increased the yield, this temperature was used for all of the extractions of this study.

The effect of disulfide bond reduction on the extraction yield was studied, using DTT at concentrations of $1 \%, 2 \%, 4 \%, 6 \%$ and $8 \%(\mathrm{w} / \mathrm{v})$ at $50{ }^{\circ} \mathrm{C}$. The addition of DTT to the 50\% 1-propanol extraction yielded $31 \%$ and $34 \%$ higher protein concentrations for wheat and barley, and 23\% higher concentration for rye compared with the unreduced extracts (Figure 1). Increasing the amount of DTT to $8 \%$ yielded somewhat higher concentrations for wheat and barley, whereas the addition of more
DTT made no difference in the yield when extracting rye prolamins.

Aqueous solutions of ethanol, 1-propanol, and 2-propanol in six different alcohol concentrations were used for the extraction of prolamins. The protein contents of the extracts were measured and compared. A $40 \%$ concentration of 1-propanol was the most efficient in extraction with all three cereals (Figure 2), extracting about $54 \% \pm 2 \%$ of prolamins of the total protein of wheat meal, $46 \% \pm 4 \%$ of the total protein content of the barley meal and $56 \%$ $\pm 2 \%$ of the total protein content of rye meal as measured by the Dumas combustion method.

\section{Optimizing the extraction temperature and duration with the bread samples}

The extraction temperature and duration of the 1-propanol extraction were optimized further with the heat-processed samples. The prolamins from the bread samples were most efficiently extracted with $40 \%$ 1-propanol and $1 \%$ DTT at $50{ }^{\circ} \mathrm{C}$ for 60 min at an extraction ratio of 1:10 (Table 2). Heating of the samples to $60{ }^{\circ} \mathrm{C}$ instead of $50{ }^{\circ} \mathrm{C}$ did not significantly increase the extraction yield nor did the sample ratio of 1:40 (data not shown). The aqueous 1-propanol solution was about $25 \%$ more
Fig.1. Effect of increasing dithiothreitol (DTT) concentration on the solubility of wheat, barley, and rye prolamins in $50 \%$ 1-propanol at $50^{\circ} \mathrm{C}$.

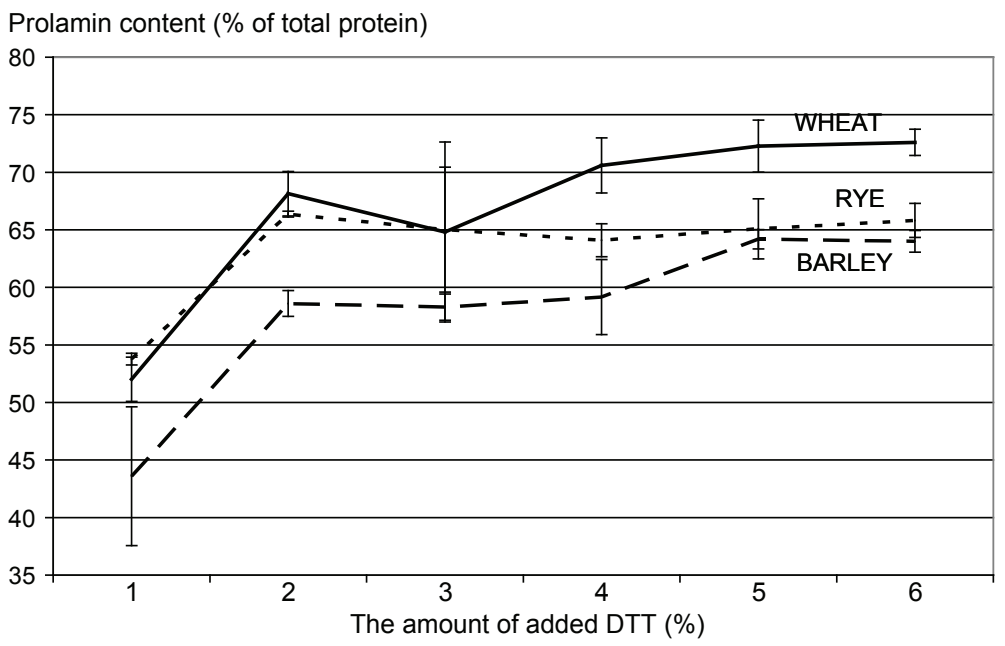


Vol. 20(2011): 206-216.

Prolamins (\% of total protein of the meal)
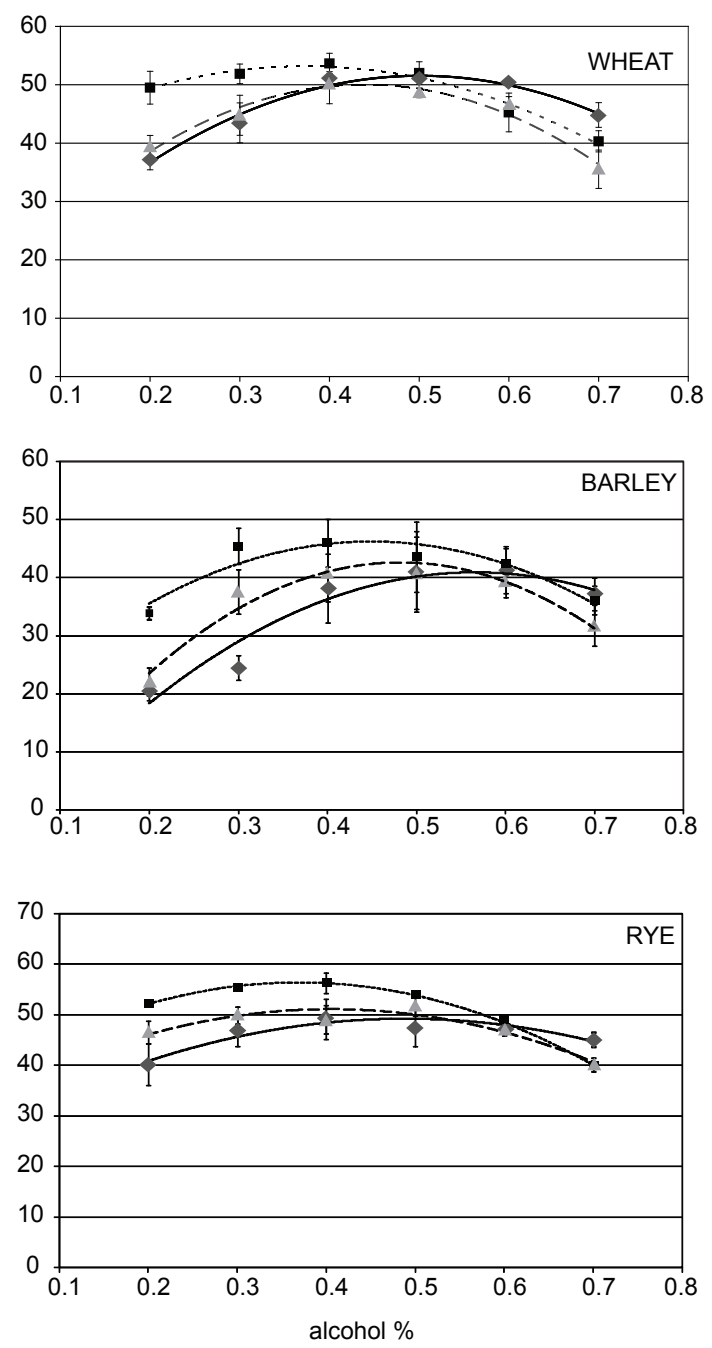

Fig. 2. Prolamins of the total protein content of barley, rye, and wheat meal when extracted with six concentrations of ethanol ( $\diamond)$, 1-propanol ( $\square)$, and 2-propanol ( $\Delta$ ). The protein contents were analyzed by the Dumas method.

efficient a solvent for the wheat prolamins from the bread sample than the cocktail solution (Table 2). All the other samples were extracted with equal efficiency with both solutions. However, extraction with 1-propanol is much faster to perform than the cocktail extraction, since it contains only one extraction step, whereas the cocktail extraction contains two steps. The Lowry method was used for comparison of the extractions with the 1-propanol and the cocktail solution, because the extra nitrogen of the cocktail solution interferes with the Dumas method. The cocktail solution contains nitrogen in the form of guanidine hydrochloride. However, it should be noted that the protein contents by the Lowry method are somewhat different from the quantities obtained by Dumas, probably due to globulin standard of the Lowry method. The results were used only for the comparative analysis of the 1-propanol and cocktail extraction.

\section{SDS-PAGE and Western blot analysis}

The prolamins of wheat, barley, and rye were separated by gel electrophoresis and blotted against three prolamin-specific antibodies. The anti- $\omega$-gliadin and R5 antibodies are commonly used in gluten analysis assays and, therefore, their abilities to recognize prolamins were compared. The polyclonal anti-gliadin antibody was used as a reference, due to its known ability to recognize prolamins on a wider scale.

Gel electrophoresis showed that the $\mathrm{C}$ hordeins of barley and a proportion of the $\mathrm{B}$ hordeins were dissolved in aqueous 1-propanol without reduc-

Table 2. Proportion of prolamins of the total protein content (dry weight) of the meal and the bread samples extracted by $40 \%$ 1-propanol with $1 \%$ dithiothreitol (DTT) at $50{ }^{\circ} \mathrm{C}$ or bythe cocktail solution, and analyzed by the Lowry method.

\begin{tabular}{llcl}
\hline Sample & & $\begin{array}{c}40 \% \text { 1-propa- } \\
\text { nol with 1\% DTT } \\
(\%)\end{array}$ & $\begin{array}{c}\text { Cocktail } \\
\text { solution } \\
(\%)\end{array}$ \\
\hline Meal & Wheat & $57.6 \pm 2.5$ & $54.4 \pm 3.0$ \\
& Barley & $31.6 \pm 0.6^{*}$ & $34.7 \pm 1.3^{*}$ \\
& Rye & $31.9 \pm 0.7$ & $32.7 \pm 0.8$ \\
Bread & Wheat & $81.4 \pm 5.7^{*}$ & $56.9 \pm 6.0^{*}$ \\
& Barley & $38.4 \pm 7.1$ & $36.8 \pm 3.3$ \\
& Rye & $32.4 \pm 5.2$ & $29.4 \pm 3.9$ \\
\hline
\end{tabular}

Statistically significant differences are indicated with an asterisk $(p<0.05)$. 
Kanerva, P. et al. Extraction of prolamins

tion (Figure 3 barley gel: lane 4). The remaining polymeric $\mathrm{B}$ hordeins required reduction before they were dissolved and a proportion remained insoluble until the SDS buffer was used for the extraction. The polymeric D hordeins dissolved in 1-propanol when reduction was used. As with the B hordeins, some of the D hordeins required extraction with the SDS buffer. Most of the rye prolamins were extracted with aqueous 1-propanol without reduction. After reduction, more of the $\gamma-75$ and
HMW secalins were extracted. Wheat prolamins clearly differed from barley and rye prolamins. Wheat contained a large number of prolamins that required reduction (Figure 3 wheat gel: lanes 5 and 6). All of the protein groups, including a proportion of the HMW glutenin subunits were, however, present in the alcohol extract even without reduction.

In Western blot analysis, the monoclonal anti- $\omega$-gliadin antibody, the monoclonal R5 antibody and the polyclonal anti-gliadin antibody

WHEAT

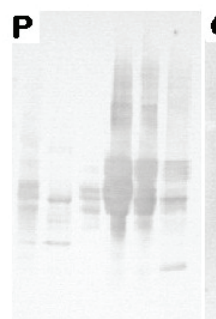

123456

BARLEY

$\mathbf{P}$

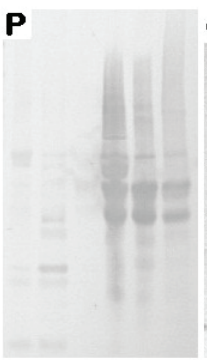

$\begin{array}{llllllllllllllllllllllll}1 & 2 & 3 & 4 & 5 & 6 & 1 & 2 & 3 & 4 & 5 & 6 & 1 & 2 & 3 & 4 & 5 & 6 & 1 & 2 & 3 & 4 & 5 & 6\end{array}$

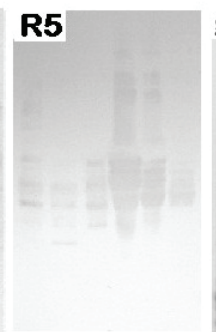

$\begin{array}{llllllllllllllllll}1 & 2 & 3 & 4 & 5 & 6 & 1 & 2 & 3 & 4 & 5 & 6 & 1 & 2 & 3 & 4 & 5 & 6\end{array}$

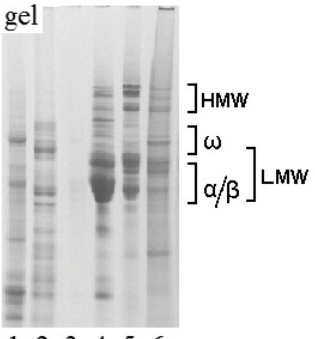

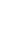


Vol. 20(2011): 206-216.

were compared with respect to their recognition of different prolamin subgroups (Figure 3). The polyclonal anti-gliadin antibody recognized all of the prolamin groups of wheat, barley, and rye, although, the recognition of $\omega$-secalins was weak (Figure 3: lanes P4). The anti-gliadin antibody also recognized some of the water- and salt-soluble proteins (Figure 3: lanes P1-3). This indicates that some prolamins may be slightly soluble in water and saline. Therefore, the preextraction of watersoluble albumins and salt-soluble globulins should not be performed to avoid the loss of prolamins. The anti- $\omega$-gliadin antibody strongly detected the $\mathrm{C}$ and D hordeins but weakly the B hordeins of barley (Figure 3 barley $\omega$ : lanes 4-6). The antibody recognized the HMW and $\gamma-75$ secalins, whereas the $\omega$-secalins appeared only faintly in the blot (Figure 3 rye $\omega$ : lanes 4-6). In the wheat extracts, the anti- $\omega$-gliadin antibody strongly detected the $\omega$-gliadins and HMW glutenin subunits (Figure 3 wheat $\omega$ : lanes 4-6). The anti- $\omega$-gliadin antibody did not cross-react with the water- and salt-soluble proteins of wheat, barley, and rye. The antibody R5 reacted strongly with the $\mathrm{B}$ hordeins, but weakly with the $\mathrm{C}$ hordeins and HMW proteins of barley (Figure 3 barley R5: lanes 4-6). Moreover, it detected all of the secalin fractions of rye (Figure 3 rye R5: lanes 4-6). In the wheat extracts, antibody R5 reacted mainly with $\alpha-, \beta$-, and $\gamma$-gliadins and low-molecular weight (LMW) glutenins (Figure 3 wheat R5: lanes 4-6). It also recognized $\omega$-gliadins and HMW glutenin subunits, but less intensively. A antibody R5 also reacted with some of the waterand salt-soluble proteins of wheat and rye (Figure 3 rye and wheat $\mathrm{R} 5$ : lanes $1-3$ ).

\section{Discussion}

The extraction characteristics are major factors affecting the reliability of the analysis of gluten contamination in gluten-free products. In the present study, extraction with 40\% 1-propanol with reduction at $50{ }^{\circ} \mathrm{C}$ for $1 \mathrm{~h}$ was the most efficient method for prolamin extraction from commercial bread samples. We also showed that the prolamin-specific antibodies differ substantially in their specificity for different prolamin subgroups.

Wheat, barley, and rye prolamins cause inflammation of the small intestine in people with gluten intolerance. Prolamins consist of various proteins that show wide recognition variability among celiac patients (Vader et al. 2002). Wheat prolamins and their role in celiac disease have been studied extensively, whereas less focus has been on barley and rye prolamins. However, these cereals, rye in particular, are widely used in Northern and Eastern Europe and constitute a major source of fiber intake. Barley and rye are also grown in the same areas as oats, which are considered safe for most celiac patients (Salovaara et al. 2009). In commercial farming and trade practices, some mixing of wheat, barley, or rye seeds may occur with the crops that are grown in the same areas, i.e. buckwheat, maize, and oats. Gluten analysis methods are based on the characteristics of wheat prolamins and, therefore, it has been questioned how accurate are the results obtained for products containing barley or rye (Kanerva et al. 2006). The total extraction of prolamins of each cereal species must be well known to obtain reliable analysis results for products containing any of the cereals that are harmful for people with celiac disease.

Three alcohols of increasing aqueous alcohol concentrations were studied for their extraction efficiency of wheat, barley, and rye prolamins. Of these, 40\% 1-propanol was the most efficient. Extraction with $60 \%$ ethanol, which is commonly used in gluten ELISAs, showed similar results for wheat as for 40\% 1-propanol; however, it was less efficient for barley and rye prolamins. Heating the samples to $50{ }^{\circ} \mathrm{C}$ instead of extracting at room temperature significantly increased the extraction yields of the prolamins. However, no significant increase in the yields was obtained when the samples were extracted at $60{ }^{\circ} \mathrm{C}$. Heating during extraction increased especially the yield of the polymeric and higher molecular weight prolamins. Reduction of the proteins with different concentrations of DTT indicated that the increase in DTT concentration increased the extraction yields. Although the high DTT concentrations slightly increased the prolamin 


\section{AGRICULTURAL AND FOOD SCIENCE}

\section{Kanerva, P. et al. Extraction of prolamins}

yield in wheat and barley, a 1\% DTT concentration was considered sufficient, since high concentrations of reducing agents interfere with antibodyantigen reactions (Doña et al. 2008). This also illustrates why SDS and urea were avoided in the extraction, regardless of their known extraction power. In addition, extraction power could be increased by increasing the temperature and, therefore, the amount of extractable protein could also be increased. However, high temperatures alter protein structure and, as a consequence, the immunoreactivity of the proteins may be lost. In the present study, the samples were extracted by a one-step procedure. Another alternative would be to use more extraction steps, which are effective in prolamin extractions (Bean et al. 1998). However, we considered a simple one-step extraction to be more practical when combining the extraction protocol with immunological gluten analysis.

Estimation of the efficacy and the yield of the extraction, with respect to the total prolamin content of the sample, is difficult, especially because the relative proportion of prolamin proteins in the total protein content varies among crops and cultivars. In seeds, the relative proportion of prolamins increases when the total protein content increases (Kirkman et al. 1982). If the prolamin content of the sample is high, a more efficient extraction protocol is needed than for the sample with low prolamin content. However, extracting the prolamins in their reduced form makes it possible to extract proteins from all prolamin groups and, thus, to increase the yield. The yield is also improved by selecting more hydrophobic solvents, since prolamins are hydrophobic due to their high content of hydrophobic amino acids. The hydrophobicity of 1-propanol is slightly higher than that of ethanol, which increases its efficiency in prolamin extraction. In the present study, the solubility of the prolamins of wheat bread increased by $25 \%$ with $40 \%$ 1-propanol, compared with the yield with the cocktail solution.

Whether prolamins are extracted with or without reduction has a significant impact on the extraction yield and prolamin composition. The prolamin subgroups of wheat, barley, and rye meal could be collected in an alcohol solution in the presence of a reducing agent. In the present study, the focus was on processed breads, since food processing may alter the solubility of prolamins, e.g. the denaturation caused by heating decreases the solubility of the proteins, whereas the depolymerization of glutenins increases their solubility in aqueous alcohols (Loponen et al. 2004). In addition, the formation of gluten network during mixing and baking induces changes in the extractability of wheat prolamins. The gluten network is formed when wheat flour is mixed with water. Mixing induces changes, such as new disulfide bonds between prolamins, that influence their extractability in different solvents (Kuktaite et al. 2004). Heating also causes such strong bonds between the prolamins that even reduction cannot result in the same solubility of the prolamins that they had before the heat treatment (Lagrain et al. 2011, Rombouts et al. 2011). All of these challenges quantitative gluten analysis, since almost inevitably some of the prolamins in processed foods remain unextracted. Another obstacle is caused by the nature of immunological analysis, since very small changes caused by the extraction conditions in the protein structure may abolish the reactivity of protein with the antibodies and leave it thus undetected. The extraction conditions must be such that the affinity of prolamins is not lost.

Comparison of the three antibodies and their cross-reactivity with the prolamins of wheat, barley, and rye revealed differences among the antibodies. The polyclonal antibody recognised all of the prolamin groups of wheat, barley and rye. The anti- $\omega$-gliadin antibody recognized mainly the high molecular weight proteins of wheat, barley and rye. Antibody R5, on the other hand, recognized mainly the medium-molecular weight prolamin groups and less intensively the high molecular weight groups. The polyclonal anti-gliadin antibody and the R5 antibody also recognized some of the water- and salt-soluble proteins of wheat and rye. Although prolamins in the native state are characterized as insoluble in water and saline solutions, some of them can be water-saline-soluble (Fu et al. 1996). Since sample extractions prior to ELISA analysis are performed directly from the meal or food samples, some of the water- and salt-soluble protein are co-extracted. 
Vol. 20(2011): 206-216.

This study showed that different prolamin subgroups have special affinities with the antibodies used, which is in agreement with the findings of Wieser and Seilmeier (1999). At low gluten concentrations, the characteristics of prolamins play a crucial role in gluten analysis since the composition of different prolamin subgroups in the sample extract plays a key role in quantification. Immunological methods are based on a chosen standard that contains certain amounts of different prolamin subgroups. Therefore, the affinity of antibody towards the standard is actually a sum of the various affinities towards the prolamin subgroups represented in the standard. If the composition of the prolamin groups in the sample distinctly differs from that of the standard, the analysis results may be unreliable. Moreover, the extraction method has a major effect on the prolamin composition and, therefore, plays an important role in the quantification of gluten. The prolamin composition of the sample is different if the proteins are extracted under reducing conditions. The current practice is to multiply the prolamin results in the gluten assays by two to obtain the total gluten content. This is done for two reasons: first, assuming that only monomeric prolamins are extracted with aqueous alcohol solutions (without reduction) and secondly, assuming that the prolamin-specific antibodies do not recognize glutenins (Valdés et al. 2003). However, significant amounts of polymeric glutenins are extracted in propanolic solutions without reduction (Fu and Sapirstein 1996), and if the proteins are extracted with reduction, the amount of polymeric proteins increases further. The Western blot analysis of this study confirmed that both the anti- $\omega$-gliadin and the R5 antibody recognized the polymeric glutenins, which were extracted with aqueous alcohols in reduced form and were visible in Figure 3 lanes 5 and 6 of the wheat blots. These characteristics enable the direct quantification of prolamins without multiplication.

Current immunological methods for gluten quantification are able to detect prolamins at very low concentrations. Low regulatory gluten limits demand high accuracy from the analysis method that is used for gluten quantification. The variability in the results obtained in ELISA methods at low gliadin concentrations raises questions as to whether the limit of $20 \mathrm{mg} \mathrm{kg}^{-1}$ of gluten is appropriate or set too low with respect to the capacity of the analytical methods. The relative error of the gluten assay with antibody R5 is 30\% (Méndez et al. 2005). The gliadin concentration of $20 \mathrm{mg} \mathrm{kg}^{-1}$ would lead to results between 14 and $26 \mathrm{mg} \mathrm{kg}^{-1}$, which is a relatively wide range when compared with the regulatory limit of $20 \mathrm{mg} \mathrm{kg}^{-1}$ for glutenfree products.

In conclusion, this study showed that the prolamins of wheat, barley, and rye from processed bread samples are most efficiently extracted with $40 \% 1$-propanol containing $1 \%$ DTT at $50{ }^{\circ} \mathrm{C}$. The use of such an efficient method in the total extraction of prolamins would improve the accuracy of current analysis, since 1) the need for multiplication of the results by two is excluded because all of the prolamin groups are extracted and detected by the prolamin-specific R5 antibody, and 2) the method uniformly extracts the prolamins of wheat, barley, and rye, which is an advantage when analyzing unknown samples and processed samples.

Acknowledgements. The authors are grateful for the financial support of the Finnish Funding Agency for Technology and Innovation (TEKES) and The Finnish Graduate School on Applied Bioscience (ABS).

\section{References}

Bean, S.R., Lyne, R.K., Tilley, K.A., Chung, O.K., \& Lookhart G.L. 1998. A rapid method for quantitation of insoluble polymeric proteins in flour. Cereal Chemistry 75:374-379.

Doña, V. V., Fossati, C. A., \& Chirdo, F. G. 2008. Interference of denaturing and reducing agents on the antigen/antibody interaction. Impact on the performance of quantitative immunoassays in gliadin analysis. European Food Research and Technology 226: 591-602.

Gellrich, C., Schieberle, P., \& Wieser, H. 2003. Biochemical characterization and quantification of the storage protein (secalin) types in rye meal. Cereal Chemistry 80: 102-109.

Fu, B.X., \& Sapirstein, H.D. 1996. Procedure for isolating monomeric proteins and polymeric glutenin of wheat flour. Cereal Chemistry 73:143-152.

Fu, B. X., Sapirstein, H. D., \& Bushuk, W. 1996. Salt-in- 


\title{
AGRICULTURAL AND FOOD SCIENCE
}

\author{
Kanerva, P. et al. Extraction of prolamins
}

duced disaggregation/solubilization of gliadin and glutenin proteins in water. Journal of Cereal Science 24: 241-246.

Kanerva, P. M., Sontag-Strohm, T. S., Ryöppy, P. H, AlhoLehto, P., \& Salovaara, H.O. 2006. Analysis of barley contamination in oats using R5 and $\omega$-gliadin antibodies. Journal of Cereal Science 44: 347-352.

Kirkman, M. A., Shewry, P. R., \& Miflin, B. J. 1982. The effect of nitrogen nutrition on the lysine content and protein composition of barley seeds. Journal of Science of Food and Agriculture 33: 115-127.

Kuktaite, R., Larsson, H., \& Johansson, E. 2004. Variation in protein composition of wheat flour and its relationship to dough mixing behaviour. Journal of Cereal Science 40:31-39.

Lagrain, B., Brijs, K., Veraverbeke, W.S. and Delcour, J.A. 2005. The impact of heating and cooling on the physicchemical properties of wheat gluten-water suspensions. Journal of Cereal Science 42:327-333.

Lagrain, B., Rombouts, I., Brijs K., \& Delcour, J.A. 2011. Kinetics of heat-induced polymerization of gliadin. Journal of Agricultural and Food Chemistry 59:2034-2039.

Lauriére, M., Charbonnier, L., \& Mossé, J. 1976. Nature et fractionnement des protéines de l'Orge extraites par l'éthanol, l'isopropanol et le $n$-propanol à des titres différents. Biochimie 58: 1235-1245.

Lohi, S., Mustalahti, K., Kaukinen, K., Laurila, K., Collin, P., Rissanen, H., Lohi, O., Bravi, E., Gasparin, M., Reunanen, A., \& Mäki, M. 2007. Increasing prevalence of coeliac disease over time. Alimentary Pharmacology \& Therapeutics 26: 1217-1225.

Loponen, J., Mikola, M., Katina, K., Sontag-Strohm, T., \& Salovaara, H. 2004. Degradation of HMW glutenins during wheat sourdough fermentations. Cereal Chemistry 81: 87-93.

Lowry, O., Rosebrough, N., Farr, A. \& Randall, R. 1951. Protein measurement with the folin phenol reagent. The Journal of Biological Chemistry 193: 265-275.

Méndez, E., Vela, C., Immer, U., \& Janssen, F. W. 2005. Report of a collaborative trial to investigate the performance of the R5 enzyme linked immunoassay to determine gliadin in gluten-free food. European Journal of Gastroenterology \& Hepatology 17: 1053-1063.

Morón, B., Cebolla, Á., Manyani, H., Álvarez-Maqueda, M., Megías, M., del Carmen Thomas, M., López, M.C., \& Sousa, C. 2008. Sensitive detection of cereal fractions that are toxic to celiac disease patients by using monoclonal antibodies to a main immunogenic wheat peptide. The American Journal of Clinical Nutrition 87: 405-414.
Osborne, T.B. 1907. The proteins of the wheat kernel. Publication No. 84. Carnegie Institution of Washington, Press of Judd \& Detweiler, Inc., Washington D.C., USA.

Rombouts, I., Lagrain, B., Brunnbauer, M., Koehler, P., Brijs, K. and Delcour, J.A. 2011. Identification of isopeptide bonds in heat-treated wheat gluten peptides. Journal of Agricultural and Food Chemistry 59:1236-1243.

Salovaara, H., Kanerva, P., Kaukinen, K., \& Sontag-Strohm, T. 2009. Oats - an overview from a celiac disease point of view. In: Arendt, E. K. \& Dal Bello, F. (Eds.). The Science of Gluten-Free Foods and Beverages. St. Paul, Minnesota, USA: AACC International Inc. p. 69-81.

Shewry, P. R., Field, J. M., Kirkman, M. A., Faulks, A. J. \& Miflin, B. J. 1980. The extraction, solubility, and characterization of two groups of barley storage polypeptides. Journal of Experimental Botany 31:393-407.

Shewry, P. R., \& Halford, N. G. 2002. Cereal seed storage proteins: structures, properties and role in grain utilization. Journal of Experimental Botany 53: 947-958.

Shewry, P. R., Miflin, B. J., \& Kasarda, D. D. 1984. The structural and evolutionary relationships of the prolamin storage proteins of barley, rye and wheat. Philosophical Transactions of the Royal Society of London B 304: 297-308.

Shewry, P. R., Parmar, S., \& Miflin, B. J. 1983. Extraction, separation, and polymorphism of the prolamin storage proteins (secalins) of rye. Cereal Chemistry 60: 1-6.

Skerritt, J. H., \& Hill, A. S. 1990. Monoclonal antibody sandwich enzyme immunoassays for determination of gluten in foods. Journal of Agricultural and Food Chemistry 38: 1771-1778.

Vader, W., Kooy, Y., Van Veelen, P., De Ru, A., Harris, D., Benckhuijsen, W., Peña, S., Mearin, L., Drijfhout, J. W., \& Koning, F. 2002. The gluten response in children with celiac disease is directed toward multiple gliadin and glutenin peptides. Gastroenterology 122: 1729-1737.

Valdés, I., García, E., Llorente, M., \& Méndez, E. 2003. Innovative approach to low-level gluten determination in foods using a novel sandwich enzyme-linked immunosorbent assay protocol. European Journal of Gastroenterology \& Hepatology 15: 465-474.

Wieser, H., \& Koehler, P. 2009. Is the calculation of the gluten content by multiplying the prolamin content by a factor of 2 valid? European Food Research and Technology 229: 9-13.

Wieser, H., \& Seilmeier, W. 1999. Reactivity of gliadin fractions and components from different wheat species in the Skerritt test. In: Stern, M. (Ed.). Proceedings of the 13th Meeting of the Working Group on Prolamin Analysis and Toxicity. Tuebingen, Germany. p. 11-18. 